\title{
PENINGKATAN KEMAMPUAN PENGELOLAAN BISNIS GURU SLB TUNA RUNGU
}

\author{
${ }^{1)}$ Lufthia Sevriana, ${ }^{2)}$ Dheka Dwi Agustiningsih, \\ ${ }^{3)}$ Asni Mustika Rani, ${ }^{4}$ Allya Roosallyn Assyofa, ${ }^{5}$ Firly Firmansyah Sumpena \\ 1,3,4,5) Universitas Islam Bandung (UNISBA), Bandung, Indonesia \\ ${ }^{2)}$ Universitas Pendidikan Indonesia (UPI), Bandung, Indonesia \\ E-mail: ${ }^{1}$ lufthia.sevriana@gmail.com, ${ }^{2}$ ddagusti@gmail.com, ${ }^{3}$ asnimustika@gmail.com, \\ ${ }^{4}$ roosallyn.allya@gmail.com, ${ }^{5}$ firlyfirman26@gmail.com,
}

\begin{abstract}
There are 36 teachers at SLB Negeri-B Cicendo Bandung (state school for students with hearing impairment), divided into: 3 kindergarten teachers, 9 elementary school teachers, 6 junior/middle school teachers, 3 high school teachers, and 15 subject teachers. They teach according to the Special Education Curriculum using sign language and written media. In order to equip the students with practical skills, Entrepreneurship Education is taught at SLB where students learn production to business management in the form of students and teachers' cooperative. Frequent constraints in their operational activities are incomes which are not in accordance with the products sold or profit reports which show different results with the calculations and cause the loss for cooperative business and the products produced cannot develop optimally. The PKM (Student Creativity Program) team seeks the solutions to these problems through training program/activities of creating business plans for SLB teachers accompanied by three mentoring meetings. The output of the activities is a business plan document prepared by SLB teachers in groups. The PKM team expects that a good and comprehensive understanding of business plan can be taught by SLB Teachers to their students and have an impact on the management of the students' pilot businesses.
\end{abstract}

Keywords: Business Plan, SLBN-B Cicendo, SLB Teachers

\begin{abstract}
Abstrak. Terdapat 36 Guru SLB di SLB Negeri-B Cicendo Bandung. Guru SLB atau pengajar di SLB tersebut terbagi menjadi 3 orang Pengajar TK, 9 Pengajar SD, 6 Pengajar SMP, 3 Pengajar SMA, dan 15 Guru Pengajar Mata Pelajaran. Para Guru SLB ini memberikan pengajaran sesuai kurikulum Pendidikan Khusus dengan menggunakan Bahasa Isyarat dan media tulisan. Pembekalan kepada siswa SLBN-B juga diberikan dalam bentuk Pendidikan Kewirausahaan, mulai dari Produksi sampai dengan Pengelolaan hasil usaha dalam wujud Koperasi Siswa dan Guru. Pada kegiatan operasionalnya kendala yang sering terjadi adalah pendapatan yang tidak sesuai dengan produk yang terjual atau Laba yang tertulis tidak sama dengan hasil perhitungan yang menyebabkan bisnis koperasi bahkan produk yang dihasilkan tidak dapat berkembang dengan optimal. Tim PKM berupaya memberikan solusi dari permasalahan tersebut melalui pelatihan pembuatan business plan bagi Guru SLB disertai tiga pertemuan pendampingan. Luaran dari kegiatan ini berupa dokumen business plan yang disusun oleh Guru SLB secara berkelompok. Harapan Tim PKM adalah agar pemahaman yang baik tentang business plan dapat diajarkan oleh Guru SLB kepada para siswa SLBN-B Cicendo yang dapat berdampak pada pengelolaan usaha rintisan siswa.
\end{abstract}

Kata Kunci: Business Plan, SLBN-B Cicendo, Guru SLB 


\section{Pendahuluan}

Sebagian warga negara Indonesia adalah penyandang disabilitas. Penyandang disabiltas adalah setiap orang yang mengalami keterbatasan fisik, intelektual, mental, dan/atau sensorik dalam jangka waktu lama yang dalam berinteraksi dengan lingkungan dapat mengalami hambatan dan kesulitan untuk berpartisipasi secara penuh dan efektif dengan warga negara lainnya berdasarkan kesamaan hak (UU No.8 Tahun 2016 Pasal 1 ayat 1). Penekanan makna disabilitas dalam konsep ini adalah adanya gangguan fungsi yang berlangsung lama dan menyebabkan terbatasnya partisipasi di masyarakat.

Lebih dari satu miliar orang atau 15 persen penduduk dunia adalah penyandang disabilitas (selanjutnya disebut PD) dan lebih dari 70 persen merupakan penduduk dalam usia kerja (LPEM, 2017). Menurut data PUSDATIN dari Kementerian Sosial pada 2010 jumlah penyandang disabilitas di Indonesia berjumlah $11,580,117$ orang. Dari jumlah tersebut $3,474,035$ di antaranya adalah penyandang disabiltas penglihatan, 3,010,830 penyandang disabilitas fisik, dan 2,547,626 penyandang disabilitas pendengaran, 1,389,614 penyandang disabiltias mental, dan 1,158,012 penyandang disabilitas kronis (ILO, 2013).

Dalam hal sebaran PD di provinsi-provinsi di Indonesia, Jawa Barat, Jawa Timur dan Jawa Tengah memiliki jumlah penyandang disabilitas tertinggi. Fakta ini tidaklah mengherankan, karena Pulau Jawa dihuni oleh 58 persen penduduk Indonesia (dihitung dari Sensus 2010). Sebanyak 18 persen penyandang disabilitas tinggal di Jawa Barat, sementara masing-masing 17 persen dan 13 persen tinggal di Jawa Timur dan Jawa Tengah.

Indonesia pada saat ini dapat dikatakan telah memiliki cukup banyak instrumen kebijakan sosial yang pada intinya mengatur tentang hak-hak orang dengan disabilitas, seperti pelayanan kesehatan, pendidikan, pekerjaan, aksesibilitas. Pada satu sisi, perkembangan ini tentu harus direspon secara positif sebagai bentuk keseriusan pemerintah Indonesia untuk menyejahterakan warga negaranya.

Oguzoglu (2009) meneliti tentang hubungan tingkat keparahan disabilitas dengan partisipasi dalam angkatan kerja. Penelitian ini menemukan bahwa tingkat disabilitas sangat berat, berat, sedang, ringan dan rendah secara signifkan mengurangi probabilitas masuk ke dalam angkatan kerja untuk laki-laki, dan hanya tingkat disabilitas sangat berat, berat dan sedang secara signifkan mengurangi probabilitas masuk ke dalam angkatan kerja untuk perempuan.

Kurang tersedianya lapangan kerja yang sesuai merupakan alasan yang paling sering dikemukakan oleh penyandang disabilitas untuk tidak berpartisipasi dalam pasar tenaga kerja. Mereka juga enggan mencari pekerjaan karena kebutuhan khusus akan akomodasi yang mungkin menjadi kendala bagi prospek untuk dipekerjakan (Loprest, 2016). Di antara negara-negara berkembang, tingkat kesenjangan pekerjaan kerap kali lebih besar di negara berpendapatan menengah dibandingkan negara berpendapatan rendah (Mitra, 2013).

Dalam kasus Indonesia, temuan Halimatussadiah et al. (2015) merupakan penelitian pertama yang 
menguraikan karakteristik angkatan kerja penyandang disabilitas. Mereka menemukan bahwa ukuran angkatan kerja penyandang disabilitas jauh lebih kecil dibandingkan ukuran angkatan kerja non-penyandang disabilitas. Mereka menyatakan bahwa tingkat pendidikan yang rendah merupakan kendala utama penyandang disabilitas untuk memasuki pasar tenaga kerja. Mereka lebih lanjut menyatakan bahwa kendala kelembagaan, misalnya, rendahnya jumlah sekolah dan infrastruktur untuk mengakses sekolah merupakan faktor di balik rendahnya tingkat pendidikan penyandang disabilitas.

Ukuran rumah tangga Non-PD cenderung lebih besar dibandingkan PD. Kondisi ini mungkin karena lebih tingginya persentase Non-PD yang berstatus menikah. Lebih rendahnya persentase PD yang menikah dibandingkan dengan NonPD mungkin disebabkan oleh lebih rendahnya probabilitas PD mendapatkan pasangan yang tepat yang bisa menerima disabilitas mereka.

Dalam hal usia, PD cenderung memiliki usia rata-rata jauh lebih tinggi daripada NonPD. Lebih tingginya probabilitas mengalami kecelakaan dan menurunnya kondisi fsik saat orang bertambah tua mungkin menjadi penyebab kondisi ini. Saat semakin menua, fungsi tubuh akan memburuk dan semakin memiliki probabilitas terkena penyakit. Akibatnya, orang akan semakin memiliki probabilitas menyandang disabilitas saat mereka bertambah tua. Kecenderungan menurunnya prevalensi disabilitas ringan dari kelompok usia 76-85 hingga kelompok usia 86-98 mungkin disebabkan oleh terkonversinya disabilitas dari disabilitas ringan menjadi berat pada usia tersebut, sehingga prevalensi disabilitas berat meningkat pada periode itu. Mengenai lokasi, PD cenderung tinggal di daerah perdesaan. Minimnya akses, fasilitas, dan kondisi kesehatan di daerah perdesaan bisa meningkatkan jumlah PD di daerah ini. Kesulitan PD untuk bermigrasi dari perdesaan ke perkotaan mungkin menjadi penyebab PD bertahan di daerah perdesaan.

Dalam hal pendidikan, hampir separuh PD tidak lulus sekolah dasar atau tidak pernah bersekolah. Jumlah ini jauh lebih tinggi dibandingkan pendidikan Non-PD, yang persentasenya untuk tidak lulus SD atau tidak pernah bersekolah hanya 12,7 persen. Fakta ini didukung oleh Lamichhane \& Kawakatsu (2015) yang menemukan bahwa anak berusia 6-18 tahun penyandang disabilitas ringan dan berat cenderung tidak bersekolah. Selanjutnya, persentase PD yang berpendidikan perguruan tinggi hanya sekitar separuh persentase Non-PD. Melihat jenis kelamin orang berusia 15 tahun ke atas, Non-PD memiliki jumlah laki-laki lebih banyak daripada perempuan, sementara penyandang disabilitas ringan dan berat cenderung memiliki jumlah perempuan lebih banyak dibandingkan laki-laki. Sebagaimana terlihat pada Tabel A.1, 50,4 persen Non-PD adalah laki-laki, sementara hanya 46,4 persen dan 48 persen penyandang disabilitas ringan dan berat adalah laki-laki. Kondisi ini mungkin disebabkan oleh diskriminasi terhadap anak perempuan atau perempuan dewasa, misalnya penyiksaan dan gizi buruk, sehingga mereka menghadapi probabilitas yang lebih tinggi untuk menjadi penyandang disabilitas (LPEM FEB UI, 2017). 
Peringkat ketiga jumlah PD terbanyak di Bandung adalah PD Rungu Wicara. PD Rungu mengalami kondisi kesulitan berkomunikasi secara verbal meskipun telah dibantu dengan alat bantu (direktorat PLB Diknas, 2004). Secara pedagogis, seorang PD Rungu Wicara membutuhkan bimbingan dan pendidikan khusus untuk mengatasi hambatan komunikasi yang dideritanya.

Berdasarkan tiga peringkat teratas PD di Bandung, PD rungu wicara tidak memiliki ciri penampilan yang dominan terlihat berbeda dibandingkan Non PD. Kalangan Non PD baru dapat melihat perbedaaan pada PD wicara jika ada interaksi komunikasi lisan diantara keduanya. Kondisi tersebut membuat PD Rungu Wicara membutuhkan bantuan pendamping yang memahami bahasa isyarat dalam berkomunikasi dengan Non PD. PD Rungu Wicara yang termasuk dalam usia sekolah, memerlukan Guru yang tidak hanya dituntut untuk sabar menjadi perantara komunikasi, akan tetapi juga diharapkan dapat memotivasi PD Rungu Wicara agar menjadi manusia yang berdaya.

Pemberdayaan PD Rungu

Wicara tidak selalu dalam konteks mempersiapkan mereka untuk siap menjadi bagian dari sektor industri formal, akan tetapi juga memberikan motivasi dan pembekalan untuk menjadi wirausaha. Pada kegiatan Belajar Mengajar, Pendidikan Kewirausahaan harus melingkupi pembelajaran mengenai konsep dan latihan kewirausahaan, inovasi, bekerja keras, motivasi dan komiten kuat, kreativitas pemecahan masalah, dan evaluasi diri oleh Alma,Buchari (2011). Untuk menumbuhkan jumlah wirausaha baru, perlu adanya sinergitas antara penguasaan IPTEK, Keahlian pengelolaan Keuangan, dan Manajemen Produksi.

Kondisi fisik para PD sering membuat mereka tidak percaya diri dalam beraktivitas secara sosial. Akan tetapi, banyak PD yang memiliki jiwa pejuang yang tangguh dan berani mengambil langkah mandiri memberikan karya nyata dalam lingkungan sosialnya. Tim PKM melihat PD Rungu Wicara di Kota Bandung masih mengalami kesulitan mendapatkan akses keuangan. Untuk itu, pemberian pelatihan penyusunan Business Plan bertujuan agar PD Rungu Wicara memiliki kemampuan membuat Business Plan yang akan memudahkan mereka mengajukan proposal bisnis kepada investor dan perbankan.

Berdasarkan latar belakang yang telah disampaikan, Tim PKM merumuskan permasalahan dalam Pengabdian tentang kondisi SLB Negeri B-Cicendo Bandun, Upaya yang sudah dilakukan oleh Guru SLB SLB Negeri B-Cicendo Bandung dalam pengelolaan unit usaha yang dijalankan bersama dengan siswa SLB dan kegiatan pelatihan pembuatan Business Plan bagi Guru SLB SLB Negeri B-Cicendo Bandung.

Business Plan dibuat oleh wirausaha, isinya menjelaskan tentang semua komponen yang diperlukan dalam memulai usaha baru atau memperluas usaha yang telah berjalan. Dalam Business Plan terdapat fungsi-fungsi perencanaan dari aspek pemasaran, teknis, keuangan dan pengelolaan sumber daya manusia. Pembuatan Business Plan dapat didampingi oleh ahli hukum, konsultan pemasaran, konsultan teknik, dan konsultan manajemen.

Business Plan merupakan realisasi yang terperinci dari gagasan 
usaha. Dalam Business Plan, terdapat uraian mengenai profil suatu usaha lengkap dengan misi dan tujuannya, gambaran operasional perusahaan, tata cara pelaporan keuangan berikut analisis yang dibutuhkan, strategi memajukan usaha, sampai menganalisis lingkungan usaha melalui analisis SWOT (Basrowi, 2011:103).

Lambing dan Peggy (2000:131) menyatakan bahwa topik-topik yang terdapat dalam sebuah perencanaan bisnis adalah: rangkuman pelaksanaan, pernyataan misi, lingkungan usaha, rencana pemasaran, tim manajemen, data keuangan, pertimbangan legal, jaminan asuransi, orang-orang kunci dalam jalannya usaha, pemasok, dan risiko yang mungkin dihadapi.

Tim PKM merangkum kebutuhan perencanaan bisnis yang dapat diaplikasikan dalam PKM ini terdiri dari, Konsep Business Plan, rangkuman profil dan misi usaha, manajemen pemasaran, manajemen produksi dan operasi, manajemen sumber daya manusia, manajemen keuangan, analisis capital budgeting, manajemen strategi, dan studi kasus penyusunan business plan dan penyampaian pelatihan oleh peserta.

Objek PKM adalah Guru SLB yang menjadi perantara komunikasi antara siswa SLB rungu wicara dengan lingkungan sosialnya. Para Guru SLB terlebih dulu harus memahami konsep tentang Business Plan agar dapat memahami urgensi dan manfaat dari pembuatan Business Plan. Business Plan tidak hanya bermanfaat bagi pelaku usaha, melainkan juga bagi calon investor, kreditor (Bank dan Lembaga keuangan lainnya), dan bagi pemasok.

Hal pertama yang harus ditampilkan dalam Business Plan adalah profil usaha. Informasi yang akan dicantumkan didalam profil usaha kurang lebih seperti biodata pada umumnya, hanya saja karena konteksnya usaha, maka harus ada nama, alamat dan nomor telepon usaha juga narahubung yang bisa diwakili oleh pemilik atau pegawai kepercayaan dalam suatu usaha. Misi yang disampaikan harus merupakan sesuatu yang dapat dicapai baik oleh pemilik maupun pegawai yang menjalankan operasional sehari-hari suatu usaha. Misi usaha yang baik harus mewakili potensi produk/jasa dan merek yang dijual, dalam artian terdapat fungsi bisnis dan sosial dari misi usaha yang dijalankan.

Suatu usaha akan tetap berjalan jika ia memiliki pembeli, dan akan langgeng jika ia memiliki pelanggan yakni pembeli produk/jasa yang loyal. Analisis pasar yang baik, perlu dilakukan untuk mendapatkan pembeli potensial yang kelak berpotensi menjadi pelanggan. Produk atau jasa yang ditawarkan harus dapat memenuhi tidak hanya keinginan, tapi juga kebutuhan calon pembeli. Sebagai produsen yang baik, pengusaha harus memahami motivasi yang membuat seseorang ingin membeli suatu produk atau jasa. Gambaran jumlah pelanggan suatu produk di pasar yang akan dituju, juga harus dihitung dengan cermat. Untuk usaha yang baru berdiri, segmentasi pasar yang akan dituju harus jelas. Penentuan segmentasi apakah berdasarkan usia, demografi, atau psikografi konsumen.

Konsumen akan tertarik pada harga murah, tapi dalam jangka panjang konsumen akan mempertimbangkan pembelian kembali jika produk atau jasa yang dibeli, termasuk produk atau jasa yang berkualitas baik. Proses produksi yang mengubah input menjadi output harus dijelaskan secara rinci dalam 
Business Plan karena hal tersebut adalah dasar dari penjaminan kualitas suatu produk atau jasa. Jelaskan bagaimana langkah-langkah pembuatan produk dan waktu yang diperlukan untuk menyelesaikan setiap langkah tersebut. Uraikan mesin, peralatan, perlengkapan yang dibutuhkan dalam proses produksi berikut kegunaan dan dimana tempat membeli semua inventaris tersebut. Setelah dibeli, harus ada pembagian tugas siapa yang dapat menggunakan mesin, peralatan, dan perlengkapan dan siapa yang bertugas untuk merawatnya.

Tugas seorang pegawai dalam usaha yang baru berdiri, bisa menjadi tugas rangkap dikarenakan anggaran yang terbatas dan jumlah konsumen yang meningkat secara bertahap. Pengusaha dapat menggolongkan pegawai berdasarkan dua tugas, yaitu tenaga kerja langsung dan tidak langsung. Tenaga kerja langsung adalah mereka yang terlibat secara langsung dalam suatu proses produksi sehingga sudah ada kualifikasi pengalaman tertentu.Tenaga kerja tidak langsung lebih banyak bertugas dalam hal pengelolaan usaha, seperti supervisor, sekretaris, dan manajer.

Anggaran perusahaan dalam mendanai gaji dan insentif para pegawai tercantum dalam aspek manajemen keuangan yakni pada perencanaan awal yang diusulkan pemilik kepada investor atau kreditor. Setelah satu bulan berjalan, akan terkumpul berbagai pekerjaan keuangan, diantaranya adalah menjurnal bukti transaksi, membukukan setiap pos keuangan dalam suatu neraca saldo agar dapat dirangkum dalam laporan laba rugi. Pemilik usaha dapat memutuskan berapa bagian laba yang bisa didapatkan investor dari perhitungan laporan laba ditahan atau bahkan laba tersebut diinvestasikan pada beragam pilihan produk investasi yang ada. Proses penyusunan laporan keuangan yang tertib pada akhirnya dapat menghasilkan gambaran tiga kegiatan inti keuangan suatu usaha, yakni kegiatan operasional, pendanaan, dan investasi.

Investasi suatu usaha dapat berupa keputusa pendanaan suatu proyek. Alat untuk menganalisis kelayakan investasi pada suatu proyek adalah capital budgeting. Pada titik tertentu, pemilik usaha harus memutuskan cara untuk memperluas usaha melalui pemilihan suatu proyek, baik itu berupa diversifikasi produk atau jasa yang dijual maupun ekspansi usaha. Capital budgeting yang paling mudah sekaligus paling mewakili proyeksi yang dibutuhkan perusahaan adalah menghitung time value of money dari perkiraan hasil usaha pada periode tertentu.

Hasil usaha (return) adalah representasi keberhasilan atau kegagalan suatu usaha. Banyak faktor yang dapat mempengaruhi keberhasilan suatu usaha. Faktor-faktor tersebut dapat berupa faktor internal (kekuatan dan kelemahan suat usaha), maupun faktor eksternal (tantangan dan hambatan dalam menjalankan usaha). Terdapat alat analisis yang dapat menguraikan dan mengubah semua faktor tersebut ke dalam bentuk angka pada suatu bagan, yaitu bagan analisis SWOT (Strengths, Weaknesses, Opportunities, Threats). Dalam jangka panjang, perusahaan yang akan bertahan adalah perusahaan yang memiliki daya saing dengan keunggulan kompetitif tertentu yakni keunikann usaha yang dimiliki dan Bagaimana keunikan itu menciptakan nilai.

Target yang ingin dicapai dengan kegiatan PKM melalui pelatihan ini yaitu adanya peningkatan pengetahuan dan 
kompetensi para Guru SLB Negeri-B Cicendo Bandung dengan pembuatan Business Plan, dan peningkatan sinergi antara potensi SLB Negeri-B Cicendo Bandung dengan Perguruan Tinggi (dalam hal ini Prodi Manajemen FEB Unisba).

Adapun manfaat dari kegiatan PKM melalui penyuluhan ini yaitu dengan adanya peningkatan kompetensi para Guru SLB SLB Negeri-B Cicendo Bandung, maka akan mampu meningkatkan kinerja usaha yang dirintis oleh Siswa dan Guru dalam bentuk Koperasi dan peningkatan kompetensi para pengrajin Kaos Sablon SUCI Bandung, maka akan mampu meningkatkan kesejahteraan Guru SLB dan Peserta SLB Negeri-B Cicendo Bandung. Peningkatan kompetensi para pengrajin Kaos Sablon SUCI Bandung, maka akan mampu meningkatkan -daya tawar produk Guru SLB SLB Negeri-B Cicendo Bandung.

Luaran yang diharapkan dari kegiatan PKM ini adalah memberikan pengetahuan dan pemahaman kepada para Guru SLB SLB Negeri-B Cicendo Bandung mengenai tahapan cara pembuatan Business Plan. Dari hasil kegiatan penyuluhan ini, tim PKM mensosialisasikan kepada pihak pemangku kepentingan (stakeholders) melalui Publikasi Ilmiah Laporan PKM yang dimuat dalam Prosiding Social and Humaniora Research Symposium Universitas Islam Bandung (SORES Unisba) serta empat dokumen Business Plan yang disusun oleh Guru SLB secara berkelompok.

\section{Metode Penelitian}

\section{Metode Pendekatan}

Metode yang digunakan dalam pelaksanaan kegiatan PKM melalui penyuluhan ini adalah dengan pendekatan dua acara yaitu pendekatan pelatihan dan pendampingan.Pelatihan dilakukan kepada Guru SLB Negeri-B Bandung yang terbagi dalam tiga sesi, yaitu pembekalan motivasi usaha oleh Firly Firmansyah Sumpena, S.E., M.M., pembekalan materi sistematika Business Plan oleh Asni Mustika Rani, S.E., M.M. dan pembekalan materi penentuan titik impas dan harga produk oleh Lufthia Sevriana, S.E., M.Si. sedangkan pendampingan dilakukan dengan mendampingi pembuatan Business Plan dengan skema satu kelompok satu mentor oleh Tim PKM.

\section{Khalayak Sasaran}

Khalyak sasaran kegiatan PKM melalui pelatihan pembuatan Business Plan ini adalah para Guru SLB Negeri$\mathrm{B}$, Cicendo Bandung. Lokasi pelatihan dan pendampingan adalah di Ruangan Guru SLB Negeri-B, Cicendo Bandung. Jumlah Peserta adalah sebanyak 36 Guru SLB Negeri-B, Cicendo Bandung.

\section{Keterkaitan Berbagai Pihak Dengan PKM}

Berbagai pihak berkepentingan yang terkait dengan kegiatan PKM ini diantaranya adalah: para Guru SLB Negeri-B, Cicendo Bandung dan Tim PKM Program Studi Manajemen Fakultas Ekonomi dan Bisnis Universitas Islam Bandung.

Bagi para Guru SLB Negeri-B, Cicendo Bandung, dengan pelatihan pembuatan business plan diharapkan dapat meningkatkan pemahaman dan 
kemampuan mereka dalam pengelolaan Bisnis Rintisan Siswa dan Guru SLB-B, yang akan berdampak pada pemningkatan pangsa pasar dalam industri yang terkait dengan produk yang dihasilkan. Sedangkan bagi Unisba kegiatan pemberian pelatihan online marketing merupakan salah satu Tri Dharma Perguruan Tinggi, yaitu memberikan kontribusi kepada masyarakat, khususnya mengenai peningkatan pemahaman dan kemampuan para para Guru SLB SLB Negeri-B, Cicendo Bandung.

\section{Tahapan Pengolahan Data}

Berikut adalah tahapan yang dilaksanakan dalam kegiatan PKM ini terdiri dari beberapa komponen kegiatan sebagai berikut :

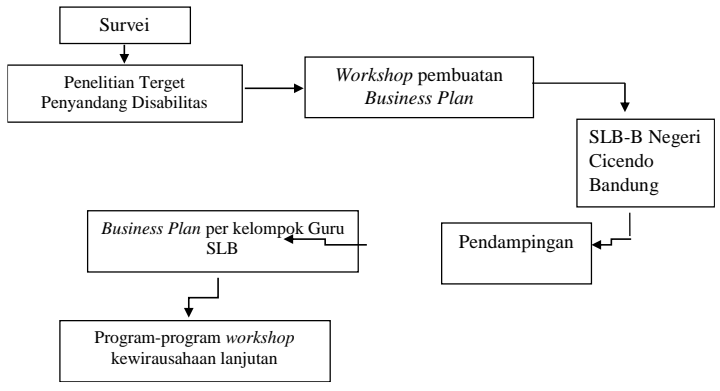

Gambar 3.1 Tahapan Kegiatan PKM

\section{Hasil dan Pembahasan}

$$
\text { Pelaksanaan Kegiatan }
$$

Pengabdian Kepada Masyarakat -Pelatihan Pembuatan Business Plan bagi Guru SLBN-B Cicendo Bandung berjalan sesuai dengan rencana yang diajukan di proposal. Setelah berdiskusi dengan Kepala Sekolah SLBN-B Cicendo Bandung, kami sepakat untuk menunda pembagian sertifikat pelatihan sampai semua peserta mengumpulkan Business Plan dengan melalui tiga kali proses pendampingan.

Pada setiap pendampingan, Tim
PKM mengarahkan cara teknis

pembuatan Business Plan. Jika ada komponen yang masih harus diperbaiki, Peserta dapat langsung memperbaiki saat pendampingan, mengingat kesibukan masing-masing pihak. Pelaksanaan Pelatihan sampai Pendampingan menghabiskan waktu satu bulan, yakni sepanjang bulan Juli 2018.

Tim PKM mengidentifikasi masalah yang perlu diatasi dengan berkunjung ke SLBN-B Cicendo Bandung pada akhir tahun 2017. Berdasarkan latar belakang keilmuan anggota Tim PKM, dan kebutuhan para Guru SLB, diputuskan untuk melaksanakan pelatihan pembuatan business plan kepada Guru SLB terlebih dahulu. Jika Guru SLB sudah dapat memahami pembuatan business plan, ilmu tersebut dapat diaplikasikan baik untuk bisnis pribadi maupun bisnis penunjang kegiatan sekolah. Bahkan akan lebih baik lagi, jika ilmu tersebut ditransfer kepada siswa dalam hal pengelolaan koperasi siswa atau pada kegiatan belajar mengajar. Unisba sebagai Perguruan Tinggi yang peduli pada kaum difabel, berupaya membina hubungan yang baik dimulai dengan SLB di Bandung. Setelah SLBN-B, Tim akan menambah mitra PKM dari berbagai SLB lainnya di Bandung.

Bisnis yang dikelola oleh SLBNB didominasi oleh bisnis kuliner hasil dari kelas tata boga. Akan tetapi Kompleksitas kegiatan SLBN-B membutuhkan lebih dari sekedar satu lini bisnis untuk menunjang pendanaan kegiatan akademik dan non akademik. Kepala Sekolah sebagai perencana strategis, meminta Tim PKM untuk menstimulus Guru SLB menyusun business plan yang potensial bagi penambahan alternatif sumber dana 
sehingga SLBN-B menjadi lebih mandiri.

Pelatihan pembuatan business plan dilaksanakan pada hari Kamis tanggal 5 Juli 2018. Pelatihan bertempat di Ruang Guru, SLBN-B, Cicendo, Bandung.

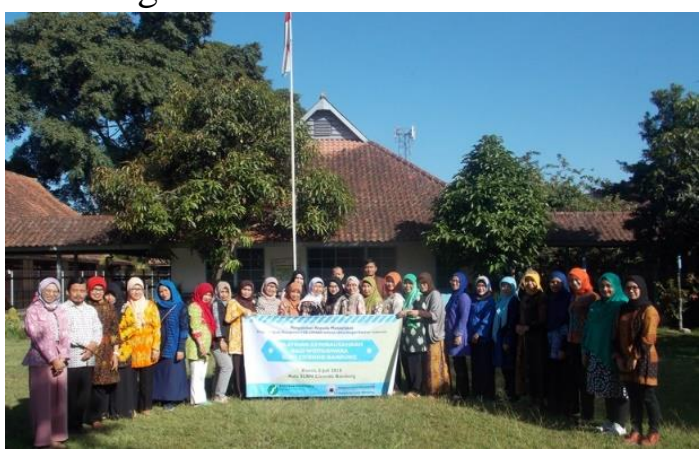

Gambar 4.1 Pelaksanaan Pelatihan Pembuatan Business Plan di SLBN-B Cicendo, Bandung

Sumber : Tim PKM Prodi Manajemen Unisba, 2018

Tim PKM memperoleh data calon peserta dari Wakil Kepala Sekolah Bidang Humas SLBN-B, Cicendo Bandung sebanyak 36 orang, akan tetapi pada saat acara berlangsung, hanya dihadiri oleh 31 peserta.

Tabel 4.1. Daftar Calon Peserta Pelatihan

\begin{tabular}{|c|c|c|c|c|c|c|c|}
\hline No & Nama & $\begin{array}{l}\text { NIP } \\
\text { NUPTK }\end{array}$ & $\begin{array}{l}\text { Tempat, } \\
\text { Tanggal lahir }\end{array}$ & $\mathbf{L} / \mathbf{P}$ & Pangkat/Gol & $\begin{array}{l}\text { Ijazah } \\
\text { Terakhir }\end{array}$ & $\begin{array}{l}\text { Guru Kelas/ } \\
\text { Mapel }\end{array}$ \\
\hline 1 & $\begin{array}{l}\text { Drs. H. Heryanto Amuda, } \\
\text { M.Phil. SNE. }\end{array}$ & 19581028.198003 .1 .010 & $\begin{array}{l}\text { Bogor, } \\
28-10-1958\end{array}$ & $\mathrm{~L}$ & IV a / Pembina & $\begin{array}{l}\text { S2/ Phil } \\
\text { SNE }\end{array}$ & $\begin{array}{ll}\text { Guru } & \text { Mapel } \\
\text { Matematika } & \\
\text { X,XI,XII } & \end{array}$ \\
\hline 2 & Neni Satriani, S.Pd & 19660416.200012 .2 .001 & $\begin{array}{l}\text { Ciamis, } \\
16-04-1966\end{array}$ & $\mathrm{P}$ & $\begin{array}{l}\text { IV b/ Pembina } \\
\text { TK. I }\end{array}$ & S1/PLB & $\begin{array}{l}\text { Guru Kelas TKLB } \\
\text { A1 }\end{array}$ \\
\hline 3 & $\begin{array}{l}\text { Lilis Ajizah, A.Md.TW., } \\
\text { S.Pd. }\end{array}$ & 19661109.199503.2.002 & $\begin{array}{l}\text { Bandung, } \\
09-11-1966\end{array}$ & $\mathrm{P}$ & IV a/ Pembina & S1/PLB & $\begin{array}{l}\text { Guru Kelas TKLB } \\
\text { A2 }\end{array}$ \\
\hline 4 & Nina Yulistiani.S.S, S.Pd & 19640706.199003.2.009 & $\begin{array}{l}\text { Purwokerto, } \\
06-07-1964\end{array}$ & $\mathrm{P}$ & $\begin{array}{l}\text { IV b/ Pembina } \\
\text { TK. I }\end{array}$ & S1/PLB & Guru Kelas TKLB B \\
\hline 5 & Euis Kurniasari, S.Pd & 19680222.199212 .2 .001 & $\begin{array}{l}\text { Indramayu, } \\
22-02-1968\end{array}$ & $\mathrm{P}$ & $\begin{array}{l}\text { IV b/ Pembina } \\
\text { TK. I }\end{array}$ & S1/PLB & Guru Kelas I A \\
\hline 6 & Uce Solihati, S.Pd & 19630830.199003 .2 .005 & $\begin{array}{l}\text { Bandung, } \\
30-08-1963\end{array}$ & $\mathrm{P}$ & $\begin{array}{l}\text { IV b/ Pembina } \\
\text { TK. I }\end{array}$ & S1/PLB & Guru Kelas I B \\
\hline 7 & $\begin{array}{l}\text { Ratna Kurniati, A.Md.TW., } \\
\text { S.Pd. }\end{array}$ & 19751130.200801 .2 .002 & $\begin{array}{l}\text { Bandung, } \\
30-11-1975\end{array}$ & $\mathrm{P}$ & $\begin{array}{l}\text { III d / Penata } \\
\text { Tk. I }\end{array}$ & S1/PLB & Guru Kelas II A \\
\hline 8 & $\begin{array}{lcc}\mathrm{Ai} & \text { Tetty } & \text { Karnia } \\
\text { Rachmawati, S.Pd } & \end{array}$ & 19601008.198303 .2 .006 & $\begin{array}{l}\text { Cianjur, } \\
08-10-1960\end{array}$ & $\mathrm{P}$ & $\begin{array}{l}\text { IV b/ Pembina } \\
\text { TK. I }\end{array}$ & S1/PLB & Guru Kelas II B \\
\hline 9 & N. Tresnanengsih, S.Pd & 197209202006042025 & $\begin{array}{ll}\text { Cirebon, } & 20- \\
09-1972 & \end{array}$ & $\mathrm{P}$ & $\begin{array}{l}\text { III d / Penata } \\
\text { Tk. I }\end{array}$ & S1/PLB & Guru Kelas III A \\
\hline 10 & $\begin{array}{l}\text { R.Rina } \\
\text { A.Md.TW., S.Pd. }\end{array}$ & 19820429.200801 .2 .007 & $\begin{array}{l}\text { Bandung, } \\
29-04-1982\end{array}$ & $\mathrm{P}$ & $\begin{array}{l}\text { III d / Penata } \\
\text { Tk. I }\end{array}$ & S1/UPI & Guru Kelas III B \\
\hline 11 & RD. Siti Maryati, S.Pd & 19620224.1986022 .004 & $\begin{array}{l}\text { Tasikmalaya, } \\
24-02-1962\end{array}$ & $\mathrm{P}$ & $\begin{array}{l}\text { IV b/ Pembina } \\
\text { TK. I }\end{array}$ & S1/PLB & Guru Kelas IV \\
\hline 12 & Dewi Indriyani, M.Pd. & 19731010.200604 .2 .004 & $\begin{array}{l}\text { Bandung, } \\
10-10-1973\end{array}$ & $\mathrm{P}$ & IV a/ Pembina & $\mathrm{S} 2 / \mathrm{PKKh}$ & Guru Kelas V \\
\hline 13 & Rini Rajani, M.Pd. & 19700902.200801 .2 .001 & $\begin{array}{l}\text { Bandung, } \\
02-09-1970\end{array}$ & $\mathrm{P}$ & $\begin{array}{l}\text { III d / Penata } \\
\text { Tk. I }\end{array}$ & $\mathrm{S} 2 / \mathrm{PKKh}$ & Guru Kelas VI \\
\hline 14 & Dedeh Rohayati, S.Pd & 19650409.198603 .2 .015 & $\begin{array}{l}\text { Bandung, } \\
09-04-1965\end{array}$ & $\mathrm{P}$ & $\begin{array}{l}\text { IV b/ Pembina } \\
\text { TK. I }\end{array}$ & S1/PLB & Guru Kelas VII A \\
\hline 15 & Witri Erdiawati SR, S.Pd & - & & $\mathrm{P}$ & - & S1 PKKh & Guru Kelas VII B \\
\hline 16 & Asep Sumarna, S.Pd & 19701130.200501 .1 .004 & $\begin{array}{l}\text { Bandung, } \\
30-11-1970\end{array}$ & $\mathrm{~L}$ & $\begin{array}{l}\text { III d / Penata } \\
\text { Tk. I }\end{array}$ & S1/PLB & Guru Kelas VIII \\
\hline 17 & Sri Wulan, S.Pd & 19610609.198305 .2 .001 & $\begin{array}{l}\text { Bandung, } \\
09-06-1961\end{array}$ & $\mathrm{P}$ & $\begin{array}{l}\text { IV b/ Pembina } \\
\text { TK. I }\end{array}$ & S1/PLB & Guru Kelas IX A \\
\hline 18 & Ernisasupiah, S.Pd & - & Riau, & $\mathrm{P}$ & - & S1/PLB & Guru Kelas IX B \\
\hline 19 & $\begin{array}{l}\text { Dra. Hj. R. Dini Megaswati, } \\
\text { M.Pd. }\end{array}$ & 19670428.199303 .2 .005 & $\begin{array}{l}\text { Cianjur, } \\
28-04-1967\end{array}$ & $\mathrm{P}$ & $\begin{array}{l}\text { IV b/ Pembina } \\
\text { TK. I }\end{array}$ & $\mathrm{S} 2 / \mathrm{PKKh}$ & Guru Kelas IX C \\
\hline
\end{tabular}




\begin{tabular}{|c|c|c|c|c|c|c|c|}
\hline 20 & Endah Mulyani, M.M.Pd. & 19591205.198303.2.009 & $\begin{array}{l}\text { Bandung, } \\
05-12-1959\end{array}$ & $\mathrm{P}$ & $\begin{array}{l}\text { IV c/ Pembina } \\
\text { Utama Muda }\end{array}$ & S2/PLB & Guru Kelas X \\
\hline 21 & Ine Rahayu, M.M.Pd. & 19650606.198603.2.008 & $\begin{array}{l}\text { Bandung, } \\
06-06-1965\end{array}$ & $P$ & $\begin{array}{l}\text { IV b/ Pembina } \\
\text { TK. I }\end{array}$ & S2/PLB & Guru Kelas XI A \\
\hline 22 & Koswara, S.Pd & 19640613.200701.1.007 & $\begin{array}{l}\text { Bandung, } \\
13-06-1964\end{array}$ & $\mathrm{~L}$ & III c / Penata & $\mathrm{S} 1 / \mathrm{PLB}$ & Guru Kelas XI B \\
\hline 23 & $\begin{array}{l}\text { Dra. Hj. Wiwien J. } \\
\text { Winajangwaty. }\end{array}$ & 19620628.198803.2.002 & $\begin{array}{l}\text { Indramayu, } \\
28-06-1962\end{array}$ & $\mathrm{P}$ & $\begin{array}{l}\text { IV b/ Pembina } \\
\text { TK. I }\end{array}$ & S1/PLB & $\begin{array}{l}\text { Guru Mapel B.Ing \& } \\
\text { Tata Boga } \\
\text { Wali Kelas XII }\end{array}$ \\
\hline 24 & $\begin{array}{l}\text { Santi } \\
\text { A.Md.TW., M.Pd. }\end{array}$ & 19770126.200501.2.010 & $\begin{array}{l}\text { Garut, } \\
26-01-1977\end{array}$ & $\mathrm{P}$ & IV a/ Pembina & $\mathrm{S} 2 / \mathrm{PKKh}$ & TIK dan B. Inggris \\
\hline 25 & Gun Gun Guntara, M.Pd. & 19711119.200501.1.005 & $\begin{array}{l}\text { Bandung, } \\
19-11-1971\end{array}$ & $\mathrm{~L}$ & IV a / Pembina & $\begin{array}{l}\text { S2/UPI } \\
\text { PKKh }\end{array}$ & $\begin{array}{l}\text { Guru Mapel } \\
\text { Kriya Kayu }\end{array}$ \\
\hline 26 & Dra. Betti Karyanti, M.Pd & 19690121.199303.2.005 & $\begin{array}{l}\text { Sumedang, } \\
21-01-1969\end{array}$ & $P$ & $\begin{array}{l}\text { IV b/ Pembina } \\
\text { TK. I }\end{array}$ & S1/PLB & Guru BKPBI \\
\hline 27 & Drs. Tasdik & 19660218.201410 .1 .001 & $\begin{array}{l}\text { Garut, } \\
18-02-1966\end{array}$ & $\mathrm{~L}$ & $\begin{array}{l}\text { III a / Penata } \\
\text { Muda }\end{array}$ & $\begin{array}{l}\text { S1/Pend. } \\
\text { Agama }\end{array}$ & $\begin{array}{l}\text { PAI IV -VII.VIII } \\
\text { B ,X-XII }\end{array}$ \\
\hline 28 & Yeyet Rochayati, S.Pd & 196206021986012001 & $\begin{array}{l}\text { Sumedang, 02- } \\
\text { 06-1962 }\end{array}$ & $\mathrm{P}$ & $\begin{array}{l}\text { IV b/ Pembina } \\
\text { TK. I }\end{array}$ & S1/PLB & $\begin{array}{lll}\text { Guru } & \text { Mapel Tata } \\
\text { Boga } & & \end{array}$ \\
\hline 29 & Iim Mandala, M.Pd. & 19750707.200604.1.013 & $\begin{array}{l}\text { Subang, } \\
07-07-1975\end{array}$ & $\mathrm{~L}$ & $\begin{array}{l}\text { III d/ } \\
\text { Penata Tk.I }\end{array}$ & $\mathrm{S} 2 / \mathrm{PKKh}$ & $\begin{array}{ll}\text { Sedang } & \text { Tugas } \\
\text { Belajar S3 } & \end{array}$ \\
\hline 30 & Yeyet Ruyati, S.Pd & & & & & & $\begin{array}{ll}\text { Mutasi } & \text { SLB } \\
\text { Solalain } & \end{array}$ \\
\hline 31 & Inayatus Sholiha, S.Pd & - & $\begin{array}{l}\text { Garut, } \\
07-02-1981\end{array}$ & $\mathrm{P}$ & - & S1/PLB & $\begin{array}{l}\text { Guru Mapel } \\
\text { Matematika \& IPA }\end{array}$ \\
\hline 32 & M. Ikhsan, S.Pd & - & $\begin{array}{l}\text { Bandung, } \\
29-10-1985\end{array}$ & $\mathrm{~L}$ & - & S1/FPOK & $\begin{array}{l}\text { Guru Mapel } \\
\text { Penjaskorkes }\end{array}$ \\
\hline 33 & Adinda Meita Putri, S.Pd & - & & $\mathrm{P}$ & - & S1 PKKh & $\begin{array}{l}\text { Guru Mapel Tata } \\
\text { Kecantikan }\end{array}$ \\
\hline 34 & Khutamy Khaerunnisa, S.Pd & - & $\begin{array}{l}\text { Bandung, 25- } \\
10-1991\end{array}$ & $P$ & - & S1/PLB & Guru Mapel TIK \\
\hline 35 & Nadia Yulanda Putri & - & $\begin{array}{l}\text { Majalengka, } \\
10-07-1995\end{array}$ & $P$ & - & S1/PLB & $\begin{array}{l}\text { Guru Mapel } \\
\text { Tata Boga }\end{array}$ \\
\hline 36 & Shintiya Erni Karyana & - & $\begin{array}{l}\text { Bandung, } 17- \\
01-1997\end{array}$ & $\mathrm{P}$ & - & S1/PLB & $\begin{array}{l}\text { Guru Mapel } \\
\text { Hasta Karya }\end{array}$ \\
\hline
\end{tabular}

Sumber: Profil SLBN-B, Cicendo Bandung.

Tanggapan dari Peserta terhadap pelatihan ini sangat baik, dan terdapat banyak pertanyaan yang menarik. Kebanyakan peserta mengajukan pertanyaan mengenai cara mengatasi masalah dalam pengelolaan bisnis mereka. Tim PKM berusaha menjawab sesuai dengan kompetensi masingmasing anggota. Antusiasme Peserta juga ditunjukan dengan kesediaan mengikuti Pendampingan sebagai lanjutan kegiatan. Peserta tidak keberatan diminta membuat Business Plan secara berkelompok. Produk yang ditampilkan dalam masing-masing Business Plan ditentukan oleh peserta, dengan catatan merupakan produk yang dapat menunjang kemandirian SLBN-B, Cicendo Bandung secara ekonomi.
Setelah melakukan pelatihan, kegiatan selanjutnya adalah melakukan kegiatan pendampingan untuk membantu peserta menyelesaikan dokumen business plan berdasarkan ide setiap kelompok. Pendampingan dilakukan selama tiga kali dengan rincian kehadiran sebagai berikut.

Tabel 4.3. Rekap Absensi Pendampingan

\begin{tabular}{|l|lll|l|}
\hline No & \multicolumn{2}{|l|}{$\begin{array}{l}\text { Pendampingan } \\
\text { Pertama }\end{array}$} & Jumlah \\
\hline 1 & $\begin{array}{l}\text { Jumat, } \\
2018\end{array}$ & 13 & Juli & 31 peserta \\
\hline 2 & $\begin{array}{l}\text { Kamis, } \\
2018\end{array}$ & Juli & 11 peserta \\
\hline 3 & $\begin{array}{l}\text { Kamis, 26 } \\
2018\end{array}$ & Juli & 15 peserta \\
\hline
\end{tabular}

Sumber: Tim PKM 
Pendampingan pertama dilaksanakan delapan hari setelah pelatihan, dihadiri oleh seluruh peserta pelatihan. Pendampingan kedua dilaksanakan enam hari setelah pendampingan pertama, hanya dihadiri oleh sebelas peserta dikarenakan banyak peserta yang sedang mendapat tugas dinas keluar sekolah. Pendampingan ketiga dilaksanakan tujuh hari setelah pendampingan kedua, dihadiri oleh 15 peserta. Meskipun pada pendampingan kedua dan ketiga tidak dalam jumlah yang sama, tapi setiap dokumen business plan sudah mengalami kemajuan, yang artinya setiap peserta berusaha menyelesaikan setiap business plan yang menjadi tugasnya.

Pada Pendampingan kedua, Tim PKM menyampaikan bahwa Peserta harus mengumpulkan print out Business Plan yang sudah disusun bersama kelompoknya. Peserta menepati kesepakatan tersebut, sehingga di akhir Pendampingan ketiga, Tim PKM mengumpulkan empat dokumen Business Plan dengan rincian sebagai berikut.

Tabel 4.4. Dokumen Business Plan hasil kerja Peserta Pelatihan

\begin{tabular}{|c|c|}
\hline Nama Dokumen & $\begin{array}{c}\text { Anggota } \\
\text { Kelompok }\end{array}$ \\
\hline Business Plan & Guru SLB \\
Jamu Impress & TKLB-SDLB \\
& Kelas 1-3 \\
\hline Business Plan & Guru SLB SDLB \\
Custom & Kelas 4-6 \\
Character & \\
Clothes for Baby & \\
and Kids & \\
\hline Business Plan & Guru SLB \\
Batik Cicendo & SMPLB Kelas 7- \\
& 9 \\
\hline
\end{tabular}

\begin{tabular}{|c|c|}
\hline $\begin{array}{c}\text { Business Plan } \\
\text { Deafy Cafe }\end{array}$ & $\begin{array}{c}\text { Guru SLB Kelas } \\
\text { SMALB Kelas } \\
10-12\end{array}$ \\
\hline
\end{tabular}

\section{Kesimpulan Dan Saran}

\section{Kesimpulan}

Berdasarkan hasil PKM dan pembahasan yang telah dilakukan, diperoleh kesimpulan bahwa Kondisi SLB Negeri B-Cicendo Bandung saat ini berfokus memproduksi berbagai macam jenis makanan hasil karya siswa dan Guru SLB di laboratorium tata boga dan mengelola hasil produksi tersebut beserta beragam snack dari supplier di Koperasi Siswa.

Upaya yang telah dilakukan oleh SLB Negeri B-Cicendo Bandung kepada pihakak ademisi / universitas / cendikiawan, kepala sekolah dan Guru SLB sangat terbuka kepada para peneliti dan tim pengabdian masyarakat untuk melakukan penelitian dan pengabdian masyarakat di SLB Negeri B-Cicendo Bandung. Bantuan yang mereka berikan berupa informasi mengenai berbagai hal yang berkaitan dengan SLB Negeri B-Cicendo Bandung. Siswa SLBN-B adalah siswa yang dibina untuk menjadi mandiri secara ekonomi dan berprestasi baik secara akademik maupun non akademik. Saat Tim PKM berkunjung ke SLB tersebut, banyak dipajang piala penghargaan atas prestasi siswa dalam bidang seni, olahraga, dan akademik. Di ruangan guru juga terdapat banyak foto kegiatan Non Akademik yang diikuti siswa. Kegiatan pelatihan pembuatan Business plan kepada Guru SLBN-B Cicendo Bandung dilakukan pada tanggal 5 juli 2018 diikuti oleh 31 peserta. Kegiatan pelatihan berupa motivasi berwirausaha, cara teknis penyusunan Business Plan, 
dan Perhitungan Titik Impas beserta cara Penentuan Harga Produk. Pemateri dalam pelatihan ini untuk sesi 1 adalah Firly Firmansyah Sumpena, S.E., M.M., untuk sesi 2 adalah Asni Mustika Rani, S.E., M.M., untuk sesi 3 adalah Lufthia Sevriana, S.E., M.Si. Semua materi diberikan dalam bentuk print out modul. Selanjutnya diadakan pendampingan sebagai tindak lanjut realisasi business plan semua peserta. Hasil akhir dari rangkaian kegiatan PKM ini berupa dokumen business plan yang disusun peserta.

\section{Saran}

Beberapa saran yang dapat disampaikan terkait dengan kegiatan PKM ini adalah Agar hasil pelatihan pembuatan Business plan terus berdampak dan berjalan baik, maka kegiatan pendampingan tidak hanya dilakukan pada saat PKM saja, alangkah baiknya jika kegiatan pendampingan ini diaplikasikan dalam wujud pendirian bisnis.

Selain kegiatan pelatihan pelatihan pembuatan Business plan, perlu dilakukan kegiatan pelatihan lain yaitu: pelatihan mengenai pelatihan pengelolaan keuangan bagi Guru SLB dan juga Siswa SLB Negeri-B, Cicendo Bandung. Semua kegiatan pelatihan ini bertujuan meningkatkan kemandirian Guru SLB dan Siswa SLBN-B Cicendo Bandung juga meningkatkan kesiapan serta kemampuan Guru SLB dan siswa SLBN B Cicendo Bandung agar meningkatkan kemampuan inovasi produknya sehingga mampu berdaya saing dipasar lokal dan pasar global.

\section{Ucapan Terima Kasih}

Dengan terlaksananya Pengabdian Masyarakat ini, maka pada kesempatan yang baik ini tim PKM mengucapkan banyak terimakasih kepada program Studi Manajemen Fakultas Ekonomi dan Bisnis Unisba yang telah membiayai pengabdian kepada masyarakat melalui kegiatan pelatihan ini, Ketua Program Studi Manajemen Fakultas Ekonomi dan Bisnis Unisba yang telah memberikan tugas kepada Tim PKM untuk melakukan pelatihan, Dekan fakultas Ekonomi dan Bisnis yang telah mendukung pelaksanaan pengabdian, Kepala Sekolah SLB Negeri B Cicendo yang telah mendukung pelaksanaan kegiatan pelatihan dan Guru SLB SLB Negeri B Cicendo yang telah berpartisipasi dalam pelatihan dan pendampingan

\section{DAFTAR PUSTAKA}

Alma, Buchari. (2011). Kewirausahaan Untuk Mahasiswa dan Umum. Bandung: Penerbit Alfabeta

Basrowi. (2011). Kewirausahaan Untuk Perguruan Tinggi. Bogor: Ghalia Indonesia

Direktorat Pendidikan Luar Biasa Departemen Pendidikan Nasional. (2004). Alat Identifikasi Anak Berkebutuhan Khusus. Jakarta: Direktorat PLB Departemen Pendidikan Nasional.

Halimatussadiah, A., Agriva, M., \& Nuryakin, C. (2015). Persons with Disabilities (PWD) and Labor Force in Indonesia : A Preliminary Study (LPEM-FEUI No. 003). Jakarta. ILO. (2013). Inklusi Penyandang Disabilitas di Indonesia. Jakarta.

Lambing, Peggy. (2000) dan Charles R.

Kuehl. Entrepreneurship, Prentice Hall, Upper Saddle River. 
Loprest, P., Rupp, K., \& Sandell, S. H. (2016). Gender , Disabilities , and Employment in the Health and Retirement Study. The Journal of Human Resources, 30(1995).

LPEM FEB UI. (2017). Laporan Akhir Memetakan Penyandang Disabilitas (PD) di Pasar Tenaga Kerja Indonesia. Jakarta: Organisasi Perburuhan Internasional.

Mitra, S. (2013). Is There a Disability Gap in Employment Rates in Developing Countries? World Development, 42(March 2012), 2843. http://doi.org/10.1016/j. worlddev.2012.05.037

Oguzoglu, U. (2009). Severity of Work Disability and Work. Bonn: IZA.Potts, B. (2005). Disability and Employment: Considering the Inportance of Social Capital. Journal of Rehabilitation, 71(3), 20-25. 